Open Access

\title{
Making and breaking in an art education makerspace
}

Robert W. Sweeny

Correspondence: sweeny@iup.edu Indiana University of Pennsylvania, Indiana, USA

\begin{abstract}
In this article, the author will outline the process of setting up a makerspace in an art education program on a US university campus. The challenges that were encountered will be discussed, as will the successful elements. In the conclusion, the author will provide the reader with a number of suggestions for integrating a makerspace into art education teacher preparation programs.
\end{abstract}

\section{Introduction}

The focus of this research in makerspaces, and the maker movement, has developed out of previous research in digital technologies. I have spent the past 10 years in academia researching the possibilities for social media, videogames, data visualization, and mobile digital technologies Sweeny (2004a, 2004b, 2015). These studies have been directly related to, and often have also been carried out within the classroom, primarily conducted with undergraduate art education students at Indiana University of Pennsylvania (IUP). IUP is the flagship university in the Pennsylvania State System of Higher Education, and has a student population of approximately 13,000. It is the only doctorategranting university in the Pennsylvania state system.

Conducting teaching and research at IUP has indicated that undergraduate art education students experience a wide range of familiarity with digital technologies. Despite the claims that those born in our current technologically advanced era are "digital natives" (Prensky 2001), a large portion of IUP students have little to no experience with digital artmaking programs or processes. Furthermore, the students that have been able to use programs, such as Photoshop, have carried out these explorations on their own.

Although the familiarity with digital artmaking is initially quite rare, many students develop a strong aptitude for such programs and processes as they enter the university art setting. While it is most common for students to use image manipulation and design software in courses such as Graphic Design, many studio areas at my university are incorporating digital tools. Digital technologies are used in the preparation of work, as in the case of using Google Sketch-Up to plan furniture design in the woodshop. They are used to execute work, as seen in the use of 3D printing in Metals and Jewelry. And they are used to document and present work in almost every studio area.

While these experiences help students to become more familiar with the use of digital technology in artmaking processes and practices, they are often presented in

(c) The Author(s). 2017 Open Access This article is distributed under the terms of the Creative Commons Attribution 4.0 International License (http://creativecommons.org/licenses/by/4.0/), which permits unrestricted use, distribution, and reproduction in any medium, provided you give appropriate credit to the original author(s) and the source, provide a link to the Creative Commons license, and indicate if changes were made. 
guided lessons that do not allow the student to explore possible alternate applications, or to troubleshoot when the result is less than desirable. This is understandable, as the technologies are being used in an applied manner. However, it remains the case that art education undergraduate students at IUP have much to learn about a wide variety of digital art media. More importantly, they have thought very little about how such media might be integrated in their teaching, in a deep and meaningful way.

It is with this primary concern in mind that discussions of digital technologies in art education courses are undertaken. The recent popularity of makerspaces, and the rhetoric that accompanies such spaces, has created a pedagogical interest in the possible teaching methodologies that makerspaces might afford. As such, the Art Education program at IUP has recently established a makerspace, housed in an art education classroom on the IUP campus. First the process of establishing the space will be described, so that I can then describe the teaching and research that it has enabled.

\section{Background}

My personal research in makerspaces and art education has been primarily carried out in two courses: ARED 318: Art in Secondary Settings, and ARED 281: Art Education and Digital Technologies. ARED 318 is offered every spring, while ARED 281 is a special topics elective course that has been offered three times. The bulk of my research has therefore been carried out in ARED 318. The research projects are typically limited to one unit within the course, which is typically 2 to 3 weeks long.

As I started to organize my research projects within these courses, I was able to obtain a variety of technological tools. First, I was provided with five Motorola Xoom tablet computers, which were used in ARED 281, which was first taught in 2008. These tablets were supplied through the College of Fine Arts Office of Technology, and were made available to student to document class time, as well as to explore possible applications of apps and social media sites. The tablets were provided to support student learning, and were not used in specific research.

Next, I was awarded a small grant through the Academic Computing Policy Advising Committee (ACPAC) Grant Competition, which funds the purchase of digital technologies for education use. This grant funded the purchase of five Apple iPod touch devices (4th generation). These have been used in my current research on mobile digital technologies, which looks to possible applications of mobile gaming in educational settings. The iPods were identified for the research because they are portable, and are equipped with WiFi, so that students can access wireless signals without having to purchase a service plan from a mobile cellular carrier. This is important, not only to minimize costs, but also to demonstrate to students the possibilities for working within a limited budget which are common in public school settings.

As these tools accumulated, I realized that they could be serving my students better if they were used more often than in the occasional focused unit of study. When the devices were not being used, they were sitting on a shelf in my office, gathering dust. While I was thinking of different ways to use the devices, I was becoming more interested in the maker movement, and the implications that this movement might hold for art education. This led me to write two grants for additional devices and technologies, including a Makerbot 3D printer, a LEGO Mindstorms kit, three LittleBits circuitry kits, and six iPad minis. 
All of these technologies are currently housed in the IUP art education makerspace that I am continuing to build. Before I describe the preliminary research that is being conducted in the space, I will provide a brief overview of the maker movement, as it is important to highlight the aspects of the movement that are relevant to this ongoing study.

\section{Makerspaces and the maker movement}

Makerspaces are generally defined as sites that allow individuals to create and collaborate on a variety of projects and activities (Peppler and Bender 2013). Makerspaces tend to be oriented towards the use of digital technologies, although most also incorporate more traditional ways of making, incorporating electronic circuit-building and woodworking, for example. In general, makerspaces have developed from two primary areas: educational reform movements, and do-it-yourself hobbyists.

First, the recent emphasis on STEM (Science, Technology, Engineering, and Math) Education in US public schools has been accompanied by an emphasis on hands-on, engaged research in areas such as computer programming, applied physics, and electrical engineering. With the "Race to the Top" grant competition, which was started in 2011, the US Department of Education identified STEM Education as one of the most urgent areas of educational emphasis. This top-down approach to makerspaces has led to the funding of makerspaces in public schools. Many of these have been established in school libraries, due to numerous reasons: the availability of communal space, the interdisciplinary nature of libraries, and the funding that is available for media (Halverson and Sheridan 2014). Make magazine, which is a publication of the O'Reilly Group, has been instrumental in bringing makerspaces into US public high schools, primarily through a grant from the Defense Advance Research Projects Agency (DARPA), which some have seen as being controversial (Dougherty 2012).

Second, makerspaces have grown from do-it-yourself (DIY) hobbyist culture. Some of the most influential examples of this are gatherings known as "Maker Faires," which for more than a decade have allowed both amateur and professional tech hobbyists to gather and share techniques, and to sell their products to the public. This DIY approach to making is seen by many as one that is dynamic and socially relevant, as projects are generally user-driven and the technological aspects are accessible and oftentimes quite inexpensive. The products of Maker Faires fit within the definition of a DIY approach to making, even though there are numerous corporate entities that are quick to use this as a marketing ploy.

The maker movement can therefore be seen at a combination of top-down and bottom-up forces that are social, economic, and artistic. Both are compelling models for inquiry within the field of art education, as they relate to contemporary approaches for learning and making. They raise a variety of issues for art educators, and the field of art education in general. As makerspaces are integrated within the curricular structures of public schools across the country, they challenge many of the hierarchies that are well-established within public education. Makerspaces are often aligned with the goals of STEM, which is also at odds with the compartmentalization of educational disciplines. It is perhaps for this reason that many visible makerspaces have been established as community art programs, as seen in Detroit, Michigan, New Brunswick, New Jersey, 
and Pittsburgh, PA. Perhaps the most renowned makerspace is NYCResistor, from which MakerBot 3D printer technology was developed.

The community setting should be taken into consideration by art educators who are considering the viability of makerspaces. The top-down, public school influence of STEM overlaps with the bottom-up approach of the DIY maker faire in the community space that is represented by the library. Libraries exist in both communities and schools. Often they function in similar ways; libraries are a conduit between education and entertainment, school and work. The importance of libraries as a liminal space will be discussed later in the chapter.

Art education has had a long history of community engagement and inquiry (See Congdon, Blandy, and Bolin 2001). If art educators are to seriously consider the impact that an art-based makerspace might have on learning in the spaces of art education, then they must also acknowledge the ways that makerspaces would change instruction and learning. Both the top-down and bottom-up aspects of makerspaces has the potential to impact the way that technology is conceived of, and taught, in the public schools. The maker movement emphasizes hands-on engagement with technology, which has the potential to demystify the process and allows greater access to the product.

The primary concepts that have therefore influenced the beginning inquiry into makerspaces are as follows. First, any exploration into the possibilities for digital technology should be guided by student interest and familiarity. Students will generally be more able to use technologies with which they are familiar. At the same time, this familiarity can often impede the rethinking of technological applications, or the critique of common use. Undergraduate art education students should be willing to subvert their own assumptions regarding applications of digital technologies. This is central to artistic inquiry, regardless of the medium or subject matter. Often, they will be asking their students to do the same, whether they are aware of this request, or not.

Second, students should work with a wide range of digital technologies, including those that are considered to be outmoded and/or irrelevant. While the technologies in the IUP makerspace continue to proliferate, the technologies that have been used in art education previously are also made available.

With these basic art educational concerns in mind, basic research was undertaken in the art educational makerspace in the Fall of 2015. What follows is a description of this process, followed by a detailed analysis of the problems and possibilities of makerspaces in art educational places

\section{Makerspaces in art educational places}

The topic of makerspaces and art education has not, at the time of this writing, been studied in depth within the field. In order to begin to collect basic data, I have started to collect survey data and interview responses within the two courses cited earlier. In ARED 281, three undergraduate art education students took part in an independent study course that allowed them to explore issues and approaches related to makerspaces. The group met for approximately $1 \mathrm{~h}$, once per week, for 15 weeks. I wanted this small group to begin to explore the space by first reading a few selected papers that dealt with makerspaces. The three writings that I chose to have students start their explorations with were: Maker Movement Spreads Innovation One Project At A Time by Kylie A. Peppler and Sophia Bender (2013); Youth, Technology, and DIY: Developing 
Participatory Competencies in Creative Media Production, by Kafai et al. (2011); and America's Edge, by Walker (2012). I selected these readings because they presented a clear definition of makerspaces, provided a brief history of the maker movement, and placed the maker movement into a broader perspective with regards to the history of progressive education and politics in the USA. None of the students had heard of the makerspace concept previously, although they had some degree of familiarity with some of the main concepts discussed in the readings: 21st Century Skills, DIY movements, and STEM/STEAM in educational settings.

Following a discussion of these readings, students were asked to catalog the materials in the makerspace. This was carried out for practical purposes of organization, as well as to allow them to see what was available to them during the special topics course. I was interested to see that none of them had any prior knowledge of the kit-based technologies (littleBits, Makey-Makey), but were familiar with the tablets and iPods, and had also used Lego sets in the past. The Mindstorms robotics set was new to them, however.

Most of the students responded to the possibilities for setting up a makerspace in their future as an art educator. They identified issues common to any art classroom, such as managing the space and keeping equipment organized. However, they were quick to point out that the digital technologies would have to be treated with more care than other materials, due to their expense, and their fragile nature. As one student wrote: "Depending on what storage is given to me, I would love to keep the equipment/tools up and stored away from the messy materials that an art room is used to seeing. Ideally, a separate corner of the room would be perfect with cleared tables." They also responded to the practical issues of chargers, power cables, and batteries.

For the third week of class, I asked students to use the materials provided in the makerspace to build something. My instructions were intentionally vague, as I did not want to place too many restrictions on this process. I simply wanted them to work with something that captured their interest.

In the fifth week, students were to identify and research an artist who used technologies similar to those found in our makerspace. The artists identified were described by the students as follows:

Researching an artist that relates to the makerspace was harder than I thought it would be. Frustrated by my lack of information, I started scrolling through my Instagram feed. I came across a post made by my cooperating teacher from pre-student teaching II. He posted about a homework assignment for his seventh grade students- create a Rube Goldberg machine. After watching the short videos his students created, I started researching Rube Goldberg. I learned that, "Rube Goldberg was a Pulitzer Prize winning cartoonist best known for his zany invention cartoons - and graduated from U. $\mathrm{Cal}$ Berkeley with a degree in engineering. It's estimated that he did a staggering 50,000 cartoons in his lifetime." He is the perfect artist to bridge art and engineering!

I did some research and came across an artist named Echo Yang. Yang takes machines and alters them to create artwork. In his one piece, he uses a hand mixer and attaches the hair of a paintbrush to the end of the wisps of the mixer. He then 
applied ink to the paintbrush hair and places the mixer in front of a piece of paper on the ground. He turns on the mixer and the brush creates these beautiful repetitive circles on the paper with the ink. The mixer is running and starts to jump a little to create this moving circular form with the ink. Yang goes on to try this with different materials like string, watercolor, and sets the mixer in different positions. Yang is altering the purpose of the machine to create art. The art is produced by the repetitive rhythm the machine makes and the artwork turns out beautifully. Yang does a series of these types of artwork and uses a vacuum and tin toy to create artwork by the machine's rhythm.

The artist that I had chosen which peaked my interest is one who worked with Legos. I thought this related nicely to the explorations we had done with the Lego tank. I had seen this artist on internet sites before, but I didn't know the depth of his work until I looked into him. His name is Jan Vormann, and the work I looked at was located primarily in Berlin. He works in war torn zones; reconstructing brick buildings and walls which have been ripped apart. Instead of inserting missing bricks, he fills in the bricks' places with blocks of Legos creating an interesting dialogue between the very painful, adult world, and a more whimsical world of play and resilience.

It is one of my core philosophies that art education should be guided primarily by the work that artists have created, are creating, and will create in the future. It is for this reason that I had assigned this research project. Unfortunately, the way that art is incorporated into current discussions of makerspaces fails to acknowledge the work of specific artists. For example, in the The Makerspace Workbench: Tools, Technologies, and Techniques for Making (Kemp, 2013), published by Make Magazine, there is a section that discusses art and makerspaces. Unfortunately, there are no specific artists mentioned. What is mentioned are examples of "artistic projects": "makerspace technology can provide a medium for a large number of artistic projects. This can include modeling, photography, computer-controlled art, light, and sound, and the list goes on" (p. 8).

This is my first recommendation, to be expanded upon in the conclusion of this chapter. Individuals working in makerspaces can learn much from artists who have been working in and between the fields of science, math, technology, and art. Just as scientists and mathematicians must be keenly aware of the research that has preceded them, so too are artists who are influences by past practices and current trends. To reduce art to a list of projects is to discredit the artists responsible for these projects.

My students were able to identify possible approaches that they could explore in the makerspace based upon their artist research. This was their next step; to carry out research in the space, and to make a finished work that was in some way related to their original interest in a particular technology or process, as well as the artists that they learned about in their research.

The creation of a work of art in the space took the remainder of the semester. Students planned, worked, reworked, started over, and finally presented their finished works. None of the students created work that they had set out to make. The first student, who had been interested in Rube Goldberg, wanted to make a Rube Goldberg machine. As she writes: "I know in the end I will create a Rube Goldberg Machine, but I do not know the route I plan on taking. Will the art be the design of the machine? Will it be the filming of 
the machine? Will it be the end task that the machine is built to do? I just don't know." She felt that this did not incorporate enough of the devices from the makerspace, so she decided instead to create a series of painting that used a pendulum to distribute paint over a flat surface. She then documented the process using the Xoom tablets, and displayed the finished paintings with the videos of the work being made.

A second student had intended on building a small robot that, using LittleBits, could create drawings and paintings. This project was based upon the work of Echo Yang. She changed this approach midway through the project, after she had run into challenges with the design of the robot: "The robot required three wheels to keep it balanced and moving but the circuits and Little Bits required too much room and weight for the robot to actually move. Most of my time went into making the robot and trying to get it to function." Her finished work consisted of a motor that was rotate halfway and then reset itself. She attached various pens and paintbrushes to the motor, and created a series of works that utilized the repetitive markmaking of the motor.

The third student was initially interested in using Legos to remake historical relics, much in the way that Jan Vormann rebuilt war-torn areas of Berlin. She was initially going to use the LittleBits synthesizer kit to repurpose a broken coffee mug, so that it could amplify sounds made with the kit. After running into issues with a broken speaker, she experimented with the concept of a homopolar motor. However, she was not able to find a magnet that was powerful enough, so she decided to build small drawing machines made of copper wire attached to a magnet. The wire held a drawing tool, and when the magnet was moved using a paired magnet that was below the drawing surface, marks were made in a semi-controlled manner.

In a series of studio journals, students were able to speak to this process, which was full of frustration, but also allowed for some satisfaction. The completion of a finished project inevitably represented the incorporation of an unfamiliar way of working. It is not uncommon for art students to become frustrated by new and unfamiliar studio processes. This is where seasoned educators can rely upon their own experiences, guiding the student to success. However, the use of digital media in makerspaces often represents new experiences for both teacher and student. It is an emergent space of learning that is created, one that shifts the expert/novice balance.

In this regard, one of the most potent results of using a makerspace in an art classroom would be that the student can rethink the common applications of familiar technologies. This can be instructive for traditional art materials as well as newer digital technologies. All students references traditional drawing and painting techniques, but did so in a way that these traditions were rethought. In all cases, the markmaking was mediated through technological intervention: the pendulum made the painting; the magnets helped to make the drawings; the motor created the repetitive marks. In the case of the digital technologies, the process of repurposing was more limited. In the only direct example of this, the student that created the pendulum paintings had never used a tablet, so she utilized the built-in video camera, and turned the tablet into a display monitor. This leads me to discuss some of the implications of this initial research.

\section{Implications for makerspaces in art educational practices}

Upon concluding this pilot study, I have been able to reflect upon some of my initial assumptions regarding makerspaces in art educational places. Each of the students was 
eager to work in the space, and maintained this eagerness throughout the semester. Of course, the flexible schedule and open-ended curriculum of the independent study allowed them to find their way through the learning process. One cannot assume that students would come to a similar result if the educational setting were dramatically different. And, although this was a small scale introduction to the makerspace, it has allowed me to identify two primary areas that I will continue to explore in future research projects.

\section{Artistic inquiry and makerspaces}

The first area for continued research is the identification of artists who work in way that are aligned with the processes and parameters of the makerspace. I will continue to explore the influence of artists who are working within similar spaces of inquiry. As I mentioned earlier, I feel it crucial to educate students about artists who are both currently working, as well as those who are of historical influence. However, it is not enough to simply ask students to find an artist who uses a certain technology or methodology. In future research, I will begin to differentiate between artists who use concepts that are drawn from makerspaces, and those artists that use the specific technologies. For example, Rube Goldberg was a cartoonist who drew magnificently complicated machines. Although he did earn a degree in engineering, he was an artist who used traditional means to make his art. Echo Yang repurposed common household machines to make his drawings. This type of appropriation is certainly important as a form of artistic expression; however, it is not clear the level to which Yang understands the modifications, from an electronic engineering perspective. And Jan Voorman used common Lego blocks to rebuilt war-torn walls in Berlin; once again, this is clever and visually powerful, but the connection to structural engineering might not be so strong.

None of these artists created works that use some of the more high-tech devices that are common to makerspaces. There is nothing inherently wrong with this; however, I feel that in the future students should be made aware of artists that use processes such as coding, engineering, and robotics. Learning to code can be a way to expand the possibilities for understanding technology in the spaces of art education (Knochel and Patton 2015).

The students involved in the makerspace were responding from their own perspectives, which are undoubtedly influenced by their own artmaking. A database of artists could be generated for students, so that they are not relying upon their own resources for such identification. An excellent historical reference would be the E.A.T. (Engineering, Art, and Technology) group, who pioneered many explorations in these fields in the early 1960s. Pairing students with partners who are familiar with ways of making that are distinct from the visual arts may also help them to see different way of working. I think that group projects between math, science, engineering, and art education students might lead to phenomenal results, if the process is open and the product is not narrowly defined.

\section{Trial and error in makerspaces}

The second area for future research has to do with understanding the process of trial and error that makerspaces facilitate. As I described, each of the students involved in 
this initial makerspace research was involved in an exploration of the media provided to them. This process inevitably involved trial and error, with the end result in each case being something that was far from predictable: "Though this project was very far from my preconceived notion of what I thought I would create with this assignment, I am glad that I had this experience of getting lost a few times, because I feel that it accurately reflected the process of a makerspace."

As previously stated, this process is not uncommon in the spaces of art education. Educational researchers often refer to the process of problem solving and internal motivation as "flow" (Csikszentmihalyi 1975). In art education, researchers have referenced obstructions (Patton 2013), constraints (Barney), and creative problem solving (Hetland, l et al. 2015). In future research I would like to compare the process of trial and error in traditional studio settings with that process in the makerspace. This will be accomplished by having the students work in a familiar media, completing a process journal as they work. Then, they will work in the makerspace, and will keep a similar journal. The two forms of writing will be compared by the students, to begin to explore the similarities and differences in creative problem solving represented by work completed in both spaces.

The processes of trial and error that is unique to artmaking can be further explored through work in the makerspace. As I have suggested elsewhere, artists using digital media can address moments when technologies begin to break down in a unique manner (Sweeny 2015). They are often not tied to the research goals of the science lab or the bottom line of the tech start-up. I am generally more interested in the dysfunctional processes that are set into motion in the makerspace: What happens when the provided technologies fail, either due to user error or mechanical malfunction?

\section{Conclusions}

I am eager to work with more undergraduate art education students in the makerspace. I see the exploration of technological dysfunction as a theme that can generate muchneeded data on the nature of inquiry in technologically infused studio spaces. This approach will guide my future inquiries in the makerspace. I am eager to document the processes that students undertake in the makerspace; not to begin to develop a doctrine for making, but to be open to aspects of the space that I was not considering. For example, one student identified possibilities for looking into the ways that makerspaces can address adaptation and special needs: "This makerspace not only allowed me to think about ways to implement this technology in the classroom, but it was a way to come up with other unique ways of art making processes. Combining these circuits can be used by all students [,] even students with poor motor skills."

I am also cognizant of the political nature of the makerspace movement. Makerspaces are usually associated with STEM/STEAM initiatives, which are tied to the world of business and commerce in a very direct manner. I am not so naïve to believe that art education is not also tied to such forces. However, the marketing of digital technologies has been commonly linked with a rhetoric of self-empowerment and utopian social development. I want to constantly be aware of these narratives, and help my students to critique the ways that digital technologies are marketed to educators.

This marketing influences every aspect of the makerspace movement, even down to the name "makerspace." Calling the use of various technologies in the art classroom a 
"makerspace" might allow for some degree of recognizability, particularly from other educators who are interested in various aspects of maker culture. However, it might also place an undue burden the use of these technologies. By assuming that all technological activities have something to do with STEM/STEAM, or that there is even a measurable educational outcome to be found in these activities, the process of inquiry is guided, at best. At worst, it is stifled.

These are issues that are complicated, to say the least. They extend far beyond my abilities to assess their impact, as an art educational researcher. These are issues that will guide my research in the near future. It is my hope that, if similar research is undertaken in other fields, by like-minded researchers, artists, scientists, and inquisitive individuals in general, that the making of makerspaces in the future will be more inclusive and more artistic. In short, that such spaces will be as open to ways of breaking as they are to ways of making.

Competing interests

The author declares that he/she has no competing interests.

\section{Publisher's Note}

Springer Nature remains neutral with regard to jurisdictional claims in published maps and institutional affiliations.

Received: 28 September 2016 Accepted: 31 March 2017

Published online: 09 May 2017

References

Congdon, K., Blandy, D., \& Bolin, P. (2001). Histories of community based Art education. Reston: National Art Education Association.

Csikszentmihalyi, M. (1975). Beyond boredom and anxiety. San Francisco: Jossey-Bass.

Dougherty, D. (2012). Makerspaces in education and DARPA. Stable URL: http://makezine.com/2012/04/04/makerspacesin-education-and-darpa/.

Halverson, E. R., \& Sheridan, K. (2014). The maker movement in education. Harvard Educational Review, 84(4), 495-504.

Hetland, L., Winner, E., Veenema, S., and Sheridan, K. (2015). Studio Thinking 2: The Real Benefits of Visual Arts Education: New York, NY: Teachers College Press.

Kafai, Y., Peppler, K., Lemke, J., \& Warschauer, M. (2011). Youth, technology, and DIY: developing participatory competencies in creative media production review of research in education. Youth Cultures, Language, and Literacy, 35, 89-119. Stable URL: http://www.jstor.org/stable/41349013.

Kemp, A. (2013). The Makerspace Workbench: Tools, Technologies, and Techniques for Making. Sebastopol, CA: Maker Media, Inc.

Knochel, A., \& Patton, R. (2015). If art education then critical digital making: computational thinking and creative code. Studies in Art Education, 57(1), 21-38.

Patton, R. (2013) The five obstructions. Published in The Journal of Social Theory in Art Education.

Peppler, K., \& Bender, S. (2013). Maker movement spreads innovation one project at a time. The Phi Delta Kappan, 95(3), 22-27. Stable URL: http://www.jstor.org/stable/23611809.

Marc Prensky, (2001) "Digital Natives, Digital Immigrants Part 1", On the Horizon, Vol. 9 Issue: 5,pp. 1-6, doi:10.1108/ 10748120110424816.

Sweeny, R. (2004a). Lines of sight in the 'network society': simulation, art education, and digital visual culture. studies in art education 46(1). Reston: NAEA.

Sweeny, R. (2004b). Three funerals and a wedding: simulation, art education, and an aesthetics of cloning. Visual Arts Research 31(61) Fall. Champaign: University of Illinois Press.

Sweeny, R. (2015). Dysfunction and decentralization in new media art education. London: Intellect Press.

Walker, M. (2012). America's edge. The Wilson Quarterly (1976-), 36(3), 36-41. Stable URL: http://www.jstor.org/stable/ 41933921. 